\title{
De Erasmus-arts 2007: filosofie, profiel en opbouw
}

\author{
Th.A.W. Splinter
}

\section{Samenvatting}

Inleiding: Een nieuw curriculum voor de artsopleiding in het Erasmus Medisch Centrum te Rotterdam wordt sedert september 2000 stapsgewijs ingevoerd. Het nieuwe curriculum heeft de naam gekregen van het beoogde eindproduct: 'De Erasmus-arts 2007'.

Filosofie: De filosofie achter Erasmus-arts 2007 is een opleiding met een impactduur van dertig tot veertig jaar, waarin het aanleren van een systematiek voor het oplossen van ( $p a-$ tiëntgebonden) problemen, het verwerven van een professionele attitude en zelfontplooiing centraal staan.

Profiel: Het basisprofiel voor de Erasmus-arts 2007 is conform het Raamplan 1994. Hieraan is toegevoegd een Erasmusprofiel van een arts die getraind is om klinische en nietklinische gegevens te integreren in denk- en handelwijze, die ervaring heeft verworven in wetenschappelijke probleemanalyse en onderzoek, die een kritische professionele attitude heeft aangeleerd ten opzichte van eigen functioneren en die zich heeft kunnen profileren in klinische en/of wetenschappelijke richting.

Opbouw van het curriculum: Er zijn vier hoofdlijnen: kern-, klinisch en keuzecurriculum en een lijn 'leren leren'. In het kerncurriculum leert de student een probleem oplossen als onderdeel van een pathofysiologisch concept volgens een begrippenschema. Het klinisch curriculum bestaat uit een algemene training met onder andere simulatiepatiënten in de eerste vier jaar van de opleiding, een algemene en speciële training met patiënten in jaar 5 en een afrondende training in jaar 6. Het keuzecurriculum (47 weken) biedt oriëntatiemogelijkheden voor de student en stapsgewijze training van probleemanalyse tot en met wetenschappelijk onderzoek. De lijn 'leren leren' omvat zowel kennis, vaardigheid als attitude. (Splinter ThAW. De Eramus-arts 2007: filosofie, profiel en opbouw. Tijdschrift voor Medisch Onderwijs 2002;21(4):188-194.)

\section{Inleiding}

De doelstellingen van de artsopleiding zijn beschreven in het Raamplan 1994 artsopleiding en vastgelegd in de Wet op de beroepen in de individuele gezondheidszorg (Wet BIG). Kort samengevat, de basisarts moet klachten en hulpvraag van een patiënt kunnen vertalen naar een (waarschijnlijkheids)diagnose en een vervolgtraject aan kunnen geven dat kan leiden tot het oplossen van het probleem. Het Raamplan 1994 geeft aan dat de basisarts, om dit doel te bereiken, getraind moet zijn in kennis, vaardigheden en attitude met betrekking tot persoonlijke, medische en wetenschappelijke aspecten en aspecten van de maatschappelijke gezondheidszorg. Dit zijn de opleidingeisen waaraan alle geneeskundefaculteiten moeten voldoen. In de manier waarop deze eisen worden ingevuld, is aan de faculteiten een zekere mate van vrijheid toegekend. Aan het Erasmus Medisch Centrum te Rotterdam wordt vanaf 1996 stapsgewijs het uit 1990 daterende curriculum van geïntegreerd blokonderwijs grotendeels vervangen en deels aangepast, om uiteindelijk te leiden tot het curriculum Erasmus-arts 2007. De naam 
Erasmus-arts 2007 verwijst naar het eindproduct van de opleiding. In dit artikel zal een beeld geschetst worden van de Erasmus-arts 2007. Hierbij wordt op hoofdlijnen ingegaan op de filosofie achter het profiel van de Erasmus-arts 2007, het profiel zelf en de opbouw van de opleiding, aangevuld met een korte opmerking over toetsing van de doelstellingen.

\section{De filosofie achter de Erasmus-arts 2007}

Tijdens de voorbereidende discussies in de profielcommissie werden de volgende overwegingen benadrukt. Na hun opleiding fungeren afgestudeerde basisartsen ongeveer dertig tot veertig jaar als arts. Daarom moeten zij tijdens hun opleiding het volgende leren: dat het belangrijk is om te blijven leren; hoe je kunt blijven leren; hoe je nieuwe informatie zoekt en selecteert; en hoe je problemen oplost.

Door de vergrijzing en de stijging van het aantal chronisch zieken en de daarmee samenhangende comorbiditeit zijn patiëntenproblemen de afgelopen jaren toegenomen in diversiteit en moeilijkheidsgraad. Om problemen te kunnen oplossen is een systematiek van belang. In die systematiek staat geïntegreerd denken voorop, dat wil zeggen het vermogen om gegevens uit onderzoek te verbinden met klinische verschijnselen en omgekeerd. Een onderdeel van die systematiek is wetenschappelijke vorming. Studenten moeten getraind worden in wetenschappelijke probleemanalyse, uitvoering van onderzoek en het kritisch analyseren en interpreteren van wetenschappelijke gegevens. Een ander onderdeel van de systematiek is de attitude: 'Weet ik genoeg om een diagnose te kunnen stellen en over te gaan tot behandeling; zo neen, hoe verkrijg ik meer informatie' en ten slotte, the proof of the pudding: 'Is het beloop van de problemen conform de verwachting?'
De arts moet rekening houden met de toenemende mondigheid van patiënten, die steeds makkelijker toegang hebben tot medische informatie en daar ook steeds meer gebruik van maken. Voor de arts zelf is de stroom van informatie uit fundamenteel en patiëntgebonden onderzoek enorm toegenomen.

Het vóórkomen van onoplosbare medische problemen vergt extra aandacht bij de communicatie met de patiënt. Elementen zoals compassie en ethiek spelen hierbij een belangrijke rol. Het ontwikkelen van een professionele attitude bij medisch studenten en artsen is traditioneel een proces van assimilatie van waarden door interactie met docenten, medestudenten, artsen, andere gezondheidswerkers en patiënten. De invloed van de vanouds belangrijke rol van de 'meester-gezelrelatie' hierin is helaas verminderd. Gestructureerde training is noodzakelijk geworden voor het verwerven van een professionele attitude. Een belangrijk onderdeel is het kunnen en moeten werken in een team van gezondheidswerkers, die samen verantwoordelijk zijn voor de totale zorgketen voor de patiënt.

Studenten volgen de basisartsopleiding en de vervolgopleiding in een periode van hun leven, die bepalend is voor hun toekomstige mogelijkheden. Eerstejaars studenten vormen een zeer heterogene groep qua aanleg en belangstelling. In de artsopleiding moeten duidelijke elementen zijn opgenomen, die de student stimuleren en uitdagen om eigen interesses en capaciteiten te ontdekken, te ontwikkelen en te verdiepen.

Samenvattend, de Erasmus-arts 2007 krijgt een opleiding waarin een systematiek voor het oplossen van (patiëntgebonden) problemen en het verwerven van een professionele attitude wordt geleerd en zelfontplooiing wordt gestimuleerd. 
Figuur 1. Opbouw van het curriculum.

\section{leren leren (levenslang leren)}

attitude, probleemoplossen en klinische vaardigheden algemene klinische training speciële klinische training

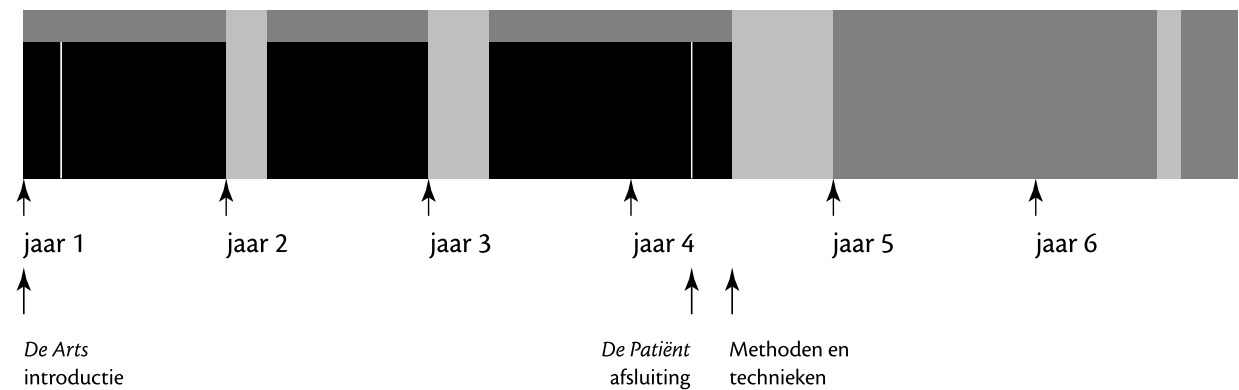

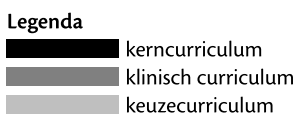

\section{Profiel van de Erasmus-arts 2007}

Bovenstaande filosofie leidt tot het volgende profiel van de Erasmus-arts 2007. De basis van het profiel, bepaald door het Raamplan 1994 artsopleiding, is een arts die zich het proces van medisch probleemoplossen heeft eigen gemaakt, een breed kennis- en vaardighedenpakket bezit en daarmee in iedere vervolgopleiding kan instromen. In combinatie met de hierboven beschreven basisfilosofie van de opleiding van de Erasmus-arts 2007, ontstaat het volgende profiel: een arts die getraind is om klinische en niet-klinische gegevens te integreren in denk- en handelwijze, die ervaring heeft verworven met wetenschappelijke probleemanalyse en onderzoek, die een kritische professionele attitude heeft aangeleerd ten opzichte van eigen functioneren en die zich heeft kunnen profileren in klinische en/of wetenschappelijke richting.

\section{Opbouw van het curriculum}

Het curriculum is opgebouwd uit vier hoofdlijnen: kerncurriculum, klinisch curriculum, keuzecurriculum en een lijn 'leren leren' (figuur 1).

Het kerncurriculum begint met de introductie 'De arts', gevolgd door een aantal pathofysiologische themata (tabel 1). Het

Tabel 1. Themata in het kerncurriculum.

Jaar 1

- Introductie De Arts

- Stoornissen in het milieu interieur

- Abnormale celgroei

Jaar 2

- Infectie- en immuunziekten

- Voeding, metabolisme en hormonale regulatie

Jaar 3

- De reproductieve cyclus

- Stoornissen in beweging, zintuiglijke waarnemingen en hogere hersenfuncties

Jaar 4

- Psychisch en sociaal disfunctioneren

- Maatschappelijke gezondheidszorg

- Epidemiologie

- Afsluiting De Patiënt 
kerncurriculum wordt afgesloten met 'De patiënt' in het vierde jaar. Het klinisch curriculum loopt van jaar 1 tot en met jaar 6. Een geïntegreerd onderdeel van de themata gedurende de eerste drie en een half jaar zijn trainingen in anamnese, lichamelijk onderzoek, attitude, ethiek en medisch probleemoplossen.
De opbouw van de themata is weergegeven in figuur 2. Elk thema bestaat uit vier delen. In alle delen staat het begrippenschema als leidraad voor de systematiek van geïntegreerd denken centraal. In het begrippenschema wordt uitgegaan van de patiënt met zijn/haar probleem, dat de student moet leren oplossen met de klas-

Figuur 2. Opbouw van alle themata en het gebruikte begrippenschema.

\begin{tabular}{llll}
\hline Hoofdconcept & Deelconcepten/ & $\begin{array}{l}\text { Exemplarische } \\
\text { problemen }\end{array}$ & $\begin{array}{l}\text { Overige zièktebeekden } \\
\text { ziektebeelden }\end{array}$ \\
Deel 1 & Deel 2 & Deel 3 & Deel 4 \\
Wat is? & $\begin{array}{l}\text { Van normaal naar } \\
\text { abnormaal naar kliniek }\end{array}$ & voor? & Toepassing kennis en \\
& & & $\begin{array}{l}\text { vaardigheden op } \\
\text { andere ziektebeelden }\end{array}$ \\
\hline
\end{tabular}

\section{Begrippenschema}

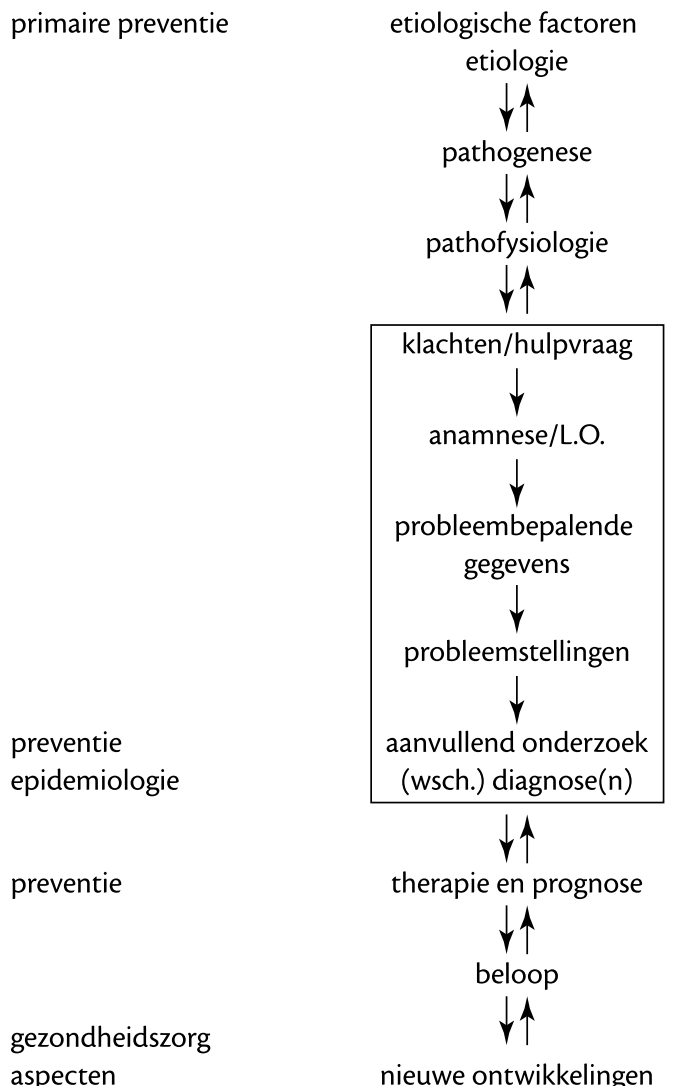


sieke methoden van anamnese, lichamelijk onderzoek, aanvullend onderzoek, et cetera. Dit is weergegeven in het omkaderde deel van het begrippenschema. Tegelijkertijd leert de student hoe zij/hij gebruik moet maken van kennis van de prekliniek epidemiologie, maatschappelijke gezondheidszorg en het beloop, om te verifiëren of het probleem op de juiste wijze is opgelost.

In deel 1 'Wat is' wordt als inleiding op het thema het hoofdconcept uitgelegd. In deel 2 'Van normaal naar abnormaal naar kliniek' worden deelconcepten behandeld. De problemen uit het Raamplan 1994 vormen hierbij de uitgangspunten. In deel 3 'Wat is kenmerkend voor?' worden de pathofysiologische deelconcepten opnieuw bestudeerd aan de hand van exemplarische ziektebeelden. Deel 4 'Toepassing van kennis en vaardigheden op andere in het thema passende ziektebeelden' is de test of de student nu in staat is om grotendeels door zelfstudie ziektebeelden te bestuderen en te begrijpen volgens de systematiek van het begrippenschema.

Het vervolg van het klinisch curriculum (figuur 3) in het vijfde en zesde jaar bestaat uit twee fasen en vier onderdelen. In het eerste onderdeel 'Algemene klinische training Erasmus' (AKTE) krijgt de co-assistent een door tutoren begeleide algemene training in de vakken heelkunde, inwendige geneeskunde, neurologie en kindergeneeskunde (HINK), welke afgesloten wordt met een stationstoets. In de speciële fase I volgt een training in specifieke vaardigheden in de disciplines psychiatrie, gynaecologie, dermatologie, oogheelkunde, KNO, huisartsgeneeskunde, maatschappelijke gezondheidszorg en revalidatie. Na AKTE en speciële fase I is de opleiding voltooid, maar is de student nog niet volgroeid. De tweede fase is daarom gericht op het ontwikkelen van ervaring, tempo, eigen verantwoordelijkheid en het werken in teamverband. Deze fase bestaat uit speciële fase II en het oudste- en het keuzeco-assistentschap. De speciële fase wordt gevolgd in de HINK-vakken en het oudste-co-assistentschap in een discipline naar keuze, mits daarvoor een erkende vervolgopleiding bestaat. De tweede fase van het klinisch curriculum is een schakeljaar avant la lettre.

Het keuzecurriculum beslaat in totaal 47 weken, waarvan 32 verspreid over de eerste vier jaar en vijftien in het zesde jaar

Figuur 3. Opbouw van het klinisch curriculum in vijf stappen van jaar $1 \mathrm{t} / \mathrm{m} 6$.

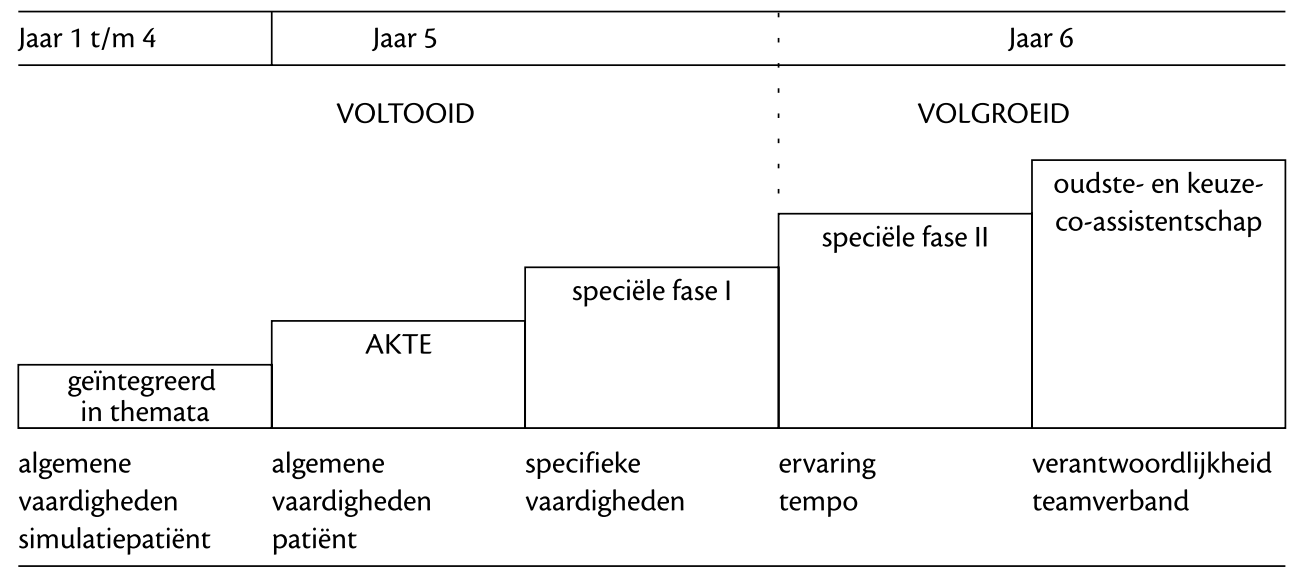


(keuze- en oudste-co-assistentschap). De eerste 32 weken vormen een lijn waarin de student in vakken naar keuze de stappen leert van probleemanalyse met behulp van literatuuronderzoek, formulering van een probleemvraagstelling, uitschrijven van een onderzoeksprotocol met kennis van methoden van medisch wetenschappelijk onderzoek tot en met uitvoering en verslaglegging van onderzoek.

Voor de geïnteresseerde en begaafde student bestaat ook de mogelijkheid om naast de reguliere studie een master-ofscience-opleiding te volgen in clinical epidemiology, molecular medicine of neurosciences. Een master-of-science-opleiding in clinical scientific research is in ontwikkeling. In de master-of-science-opleidingen worden dezelfde stappen gevolgd als in het keuzecurriculum, maar met meer diepgang. Zij zijn bedoeld als opstap naar een promotie.

Ten slotte de lijn 'leren leren'. De doelen van deze lijn zijn de student te leren dat kennis, benodigd voor het oplossen van een probleem, een integratie moet zijn van klinische en niet-klinische gegevens, voortgekomen uit wetenschappelijk onderzoek. In de loop van het curriculum neemt de nadruk op zelfstudie toe. De student wordt gestimuleerd om een eigen leerstijl te ontwikkelen waarmee de systematiek van het probleemoplossen wordt eigen gemaakt. De attitude 'Weet ik genoeg om tot handelen over te gaan?' is de kritische rode draad door de lijn 'leren leren'.

De belangrijkste doelstelling van Erasmus-arts 2007 is een arts op te leiden, die getraind is in een systematiek van probleemoplossen waarin het probleem als onderdeel van een groter concept op wetenschappelijke wijze wordt geanalyseerd met gebruikmaking van klinische en nietklinische kennis en vaardigheden. Om na te gaan of deze doelstelling wordt bereikt, wordt er, naast de toetsing van kennis, vaardigheden en attitude per onderdeel, gestreefd naar jaartoetsen voor de jaren 1 tot en met 5 en een portfolio. In de jaartoetsen staat casusoplossing centraal en het portfolio bestaat uit longitudinale beoordelingen van professioneel gedrag en handelen.

\section{Ten slotte}

De eerste beoordelingen van Erasmusarts 2007 door studenten worden gekenmerkt door de trefwoorden leuk, uitdagend, boeiend en zwaar. Verschillende studieweken overschrijden de veertig uur. Voor sommige docenten heeft het geïntegreerde, disciplineoverschrijdende onderwijs een vanzelfsprekende meerwaarde, voor anderen is het een leerproces. Wij hopen en verwachten dat de filosofie achter Erasmus-arts 2007 door de opbouw en uitvoering van het curriculum zal worden waargemaakt. Logischerwijs zou dezelfde filosofie de grondslag moeten vormen voor de curricula van de vervolgopleidingen waarin de Erasmus-arts haar/zijn medische educatie zal voortzetten.

\section{De auteur:}

Prof. dr. Th.A.W. Splinter is internist-oncoloog, directeur van het Opleidingsinstituut Geneeskunde en onderwijsdecaan in het Erasmus Medisch Centrum te Rotterdam.

\section{Correspondentieadres:}

Prof. dr. Th.A.W Splinter, Erasmus Universiteit Rotterdam, Postbus 1738, 3000 DR Rotterdam, Tel: 010-4087511,splinter@oncd.azr.nl. 


\section{Summary}

Introduction: At the Erasmus Medical Centre, Rotterdam, the Netherlands, a new undergraduate medical curriculum, entitled 'the Erasmus doctor 2007', is gradually being introduced. The first students entered the new curriculum in September 2000.

Philosophy: Underlying the curriculum is the following philosophy: the impact of the curriculum will extend over a period of 30-40 years; the core issues are: a systematic approach to (patient) problem solving, professional attitude and self-realisation of students.

Profile: Based on 'Blueprint 1994, final objectives of medical education in the Netherlands', the profile of the Erasmus-doctor 2007 is that of a doctor who has been trained to integrate clinical and nonclinical data in his/her thinking and acting, has experience in scientific problem analysis and research, has acquired a critical professional attitude towards his/her personal functioning and has learned to pursue his or her personal clinical and/or scientific interests.

Curricular structure: The four main components are: the core curriculum, the clinical curriculum, the elective curriculum and the 'learning to learn' track. The core curriculum teaches students to solve problems within a pathophysiological concept and using a specific conceptual framework. The clinical curriculum offers general training using standardised patients during years 1 through 4, general and discipline-related training in year 5 and finishing training in year 6. The elective curriculum (47 weeks) takes students, in topics of their own choice, in several steps from analysing problems using data from the literature to conducting a scientific study. The 'learning to learn' track addresses knowledge, skills and attitudes. (Splinter ThAW. The Erasmus-doctor 2007: philosophy, profile and curriculum. Dutch Journal of Medical Education 2002;21(4):188-194.) 